\title{
The profile of respiratory pathogens in induced sputum of elderly and non-elderly asthmatics
}

\author{
ALEKSANDRA WARDZYŃSKA ${ }^{1}$, MAŁGORZATA PAWEŁCZYK ${ }^{1}$, ANNA GEOBIŃSKA ${ }^{l}$, \\ JOANNA S. MAKOWSKA', MAREK L. KOWALSKI
}

${ }^{1}$ Department of Immunology, Rheumatology and Allergy, Medical University of Lodz, Lodz, Poland

${ }^{2}$ Rheumatology Clinic, Medical University of Lodz, Lodz, Poland

\begin{abstract}
Introduction: Respiratory pathogens are thought to be involved in the pathogenesis and exacerbations of asthma at all ages; however, little is known about the airway microbiome in the elderly.

Aim of the study: To identify respiratory pathogens in the induced sputum (IS) of elderly asthmatics, and to determine the association between pathogens and the markers of asthma activity.

Material and methods: Twenty-nine subjects with stable asthma, 15 above 65 years of age and 14 aged 30-49 years, underwent clinical evaluation, fractional exhaled nitric oxide measurement, and sputum induction. Pathogens were detected by multiplex reverse transcription polymerase chain reaction. The periostin concentration of IS supernatants was measured by enzyme-linked immunosorbent assay. Serum eosinophil cationic protein and total IgE levels were measured by ImmunoCAP.

Results: Elderly patients, as compared to non-elderly, had significantly higher eosinophilia in IS, although other markers of eosinophilic inflammation were comparable. Half of the subjects were positive for Haemophilus influenzae. Chlamydophila pneumoniae was found in two subjects. Respiratory viruses were detected in more than $70 \%$ of patients. The detection rates and profiles of atypical bacteria and respiratory viruses were similar in both groups. Only in the elderly asthmatics was influenza A positivity associated with lower predicted $F V C \%, R S V$ A positivity connected with decreased tIgE concentration, and RSV B positivity related to a lower percentage of lymphocytes in IS.

Conclusions: Despite the existence of differences in some clinical and inflammatory characteristics of asthma between elderly and non-elderly asthmatics, the pathogen detection rates in the IS from the two groups are similar.
\end{abstract}

Key words: asthma, elderly, pathogens, induced sputum.

(Centr Eur J Immunol 2019; 44 (4): 384-389)

\section{Introduction}

Ageing is often characterised by a progressive decline in immune response, resulting in increased susceptibility to infections and poor response to vaccination [1]. Clinical observations suggest that lower respiratory tract infections may contribute to the pathogenesis of asthma and are important triggers for asthma exacerbations [2]. Asthma in the elderly seems to be a distinct phenotype with higher severity and exacerbation rates [3], which may be associated with the deterioration of immune function observed in the airways in the aged population [4].

The airway microbiome might have a profound role on the development, persistence, and clinical course of chronic inflammatory diseases like asthma and chronic obstructive pulmonary disease [5]. The presence of respiratory viruses during childhood has been identified as a significant risk factor for asthma in adolescences and adults [6], while similar observations have been made for atypical bacteria [7]. Viruses, such as rhinovirus, respiratory syncytial virus, or parainfluenza viruses, are the most common causative factors for asthma exacerbation [8]. In clinically stable periods of asthma, both viruses and bacteria are detected in the airways $[9,10]$, but the significance of the persistent presence of those pathogens in the airways remains unclear. While the majority of studies indicate that the detection rate of respiratory viruses in patients with asthma and healthy subjects is similar [10], they have been found to differ with regard to the bacterial composition of the airways [11].

Information on the respiratory pathogens of the lower airways and their relationship with the nature of asthma

Correspondence: Marek L. Kowalski, Department of Immunology, Rheumatology and Allergy, Medical University of Lodz, 251 Pomorska St., 92-213 Lodz, Poland, e-mail: marek.kowalski@csk.umed.lodz.pl Submitted: 20.07.2017; Accepted: 7.05.2018 
in elderly asthmatics is limited, mostly because of the risk and inconvenience associated with direct and invasive methods of airway lumen sampling. Induced sputum (IS) allows for non-invasive assessment of lower airway inflammation and can be employed to detect respiratory pathogens in the lower respiratory tract. This technique was chosen for the present study, to test the hypothesis that elderly patients with asthma display a different profile of respiratory pathogens in the airways as compared to non-elderly asthmatics, and that this profile may be related to local airway and/or systemic inflammation.

\section{Material and methods}

\section{Patients}

Twenty-nine clinically stable, non-smoking patients with moderate or severe persistent asthma, 15 elderly (above 65 years of age) and 14 non-elderly (aged 30-49 years), were included to the study. None of the individuals demonstrated any symptoms of infection or had used antibiotics or oral corticosteroids for six weeks prior to the procedure. The level of asthma control was established according to Global Initiative for Asthma (GINA) 2011 guidelines [12] and assessed by the Asthma Control Test (ACT) [13]. Severe asthma was defined according to the American Thoracic Society (ATS) Workshop 2000 criteria [14]. Spirometry was performed according to European Respiratory Society (ERS) standards [15], using a PNEUMO RS spirometer (Abcmed Artmed, Kraków, Poland). The panel of skin prick tests (Allergopharma, Reinbek, Germany) included the following allergens: Dermatophagoides pteronyssinus, Dermatophagoides farinae, cat, dog, rabbit, hamster, guinea pig, rat, swine, birch, grass mix, mugwort, plantain, Alternaria tenuis, and Cladosporium herbarum. A positive result was defined as a wheal of $3 \mathrm{~mm}$ or more in diameter. Atopy was diagnosed as the presence of at least one positive skin test.

\section{FeNO measurement}

FeNO was measured by using the online single breath method with NIOX (Aerocrine, Solna, Sweden), according to ATS guidelines [16]. The measurement was performed before the sputum induction.

\section{Sputum induction}

Sputum induction was performed according to Pin et al. with some modifications $[17,18]$. Briefly, patients received $200 \mu \mathrm{g}$ of salbutamol from a metered dose inhaler followed by inhalation of increasing doses of hypertonic saline solution $(3 \%, 4 \%, 5 \%)$ using an ultrasonic nebuliser UltraNeb (Devilbiss Health Care Inc., Somerset, USA). Patients were asked to expectorate sputum after gargling mouthwash. Spirometry was performed before the procedure, 15 minutes af- ter salbutamol inhalation, and every seven minutes after the start of the saline nebulisation. When their FEV1 decreased by $20 \%$ or more, the sputum induction was stopped.

\section{Processing and analysis of the induced sputum}

The sputum sample was kept on ice and processed within two hours. Dithiothreitol (DTT) (Sigma Aldrich, St Louis, USA) was added to the selected plaques of sputum and mixed for $15 \mathrm{~min}$ on ice. The sample was filtered using a 52- $\mu \mathrm{cm}$ nylon gauze (Surtex, Lodz, Poland). The total cell count was measured using a haemocytometer and centrifuged. The cell pellets were resuspended with phosphate-buffered saline (PBS), and $75 \mu$ of this cell suspension was used to perform the cytospin slides stained with RapiHem solution, a variant of May-Grünwald-Giemsa staining (Aqua-Med, Lodz, Poland). Only smears with less than $50 \%$ of non-squamous cells were considered to be adequate for the differential cell counting. On each slide, 300 cells were counted, and the macrophage, lymphocyte, neutrophil, and eosinophil values were expressed as percentages of the total number of inflammatory cells. The supernatants were stored frozen at $-80^{\circ}$ for further analysis.

\section{Detection of bacteria}

Bacterial DNA was extracted from $200 \mu \mathrm{l}$ of each sputum specimen using a QIAamp MinElute Virus Spin Kit (Qiagen, Valencia, USA), according to the manufacturer's instructions. A qualitative in vitro test, Seeplex PneumoBacter ACE Detection (Seegene, Seoul, South Korea) was used for the detection of six pathogens: Mycoplasma pneumoniae (MP), Legionella pneumophila (LP), Streptococcus pneumoniae (SP), Haemophilus influenzae (HI), Bordetella pertussis (BP), and Chlamydophila pneumoniae (CP). The multiplex PCR products were visualised by electrophoresis on $2 \%$ agarose gel.

\section{Detection of viruses}

Viral DNA or RNA was extracted from sputum using a QIAamp ${ }^{\circledR}$ MinElute ${ }^{\circledR}$ Virus Spin Kit (Qiagen), according to the manufacturer's instructions. To synthesise cDNA, reverse transcription was performed using a RevertAid $\mathrm{H}$ Minus First-Strand cDNA Synthesis Kit (Thermo Fisher Scientific Inc., Waltham, USA). Each cDNA was subjected to multiplex PCR using a SEEPLEX RV15 ACE Detection Kit (Seegene), according to the manufacturer's instructions. The multiplex PCR detected rhinoviruses (HRV) and enteroviruses (HEV), parainfluenza viruses 1 (PIV1), 2 (PIV2), 3 (PIV3), and 4 (PIV4), influenza viruses $A($ FluA) and B (FluB), respiratory syncytial viruses A (RSVA) and B (RSVB), coronaviruses (229E/NL63 and OC43), adenovirus (AdV), human metapneumovirus (MPV), and human bocaviruses 1/2/3/4 (HBoV). The multiplex PCR products were visualised by electrophoresis on $2 \%$ agarose gel. 


\section{Inflammatory markers in serum}

The serum concentrations of total $\operatorname{IgE}(\mathrm{kU} / \mathrm{l})$ were determined by ImmunoCAP Total IgE (Phadia AB, Uppsala, Sweden), and the concentrations of $\mathrm{ECP}(\mu \mathrm{g} / \mathrm{l})$ were determined using ImmunoCAP ECP (Phadia AB, Upsala, Sweden), according to the manufacturer's instructions.

\section{Periostin in induced sputum supernatants}

Periostin was measured in the IS supernatants using an enzyme-linked immunoassay (USCN Life Science Inc., Wuhan, Hubei, China), according to the manufacturer's instructions.

\section{Statistical analysis}

Comparisons between the groups were performed with the non-parametric Mann-Whitney $U$ test. Spearman rank correlation was used to evaluate the correlation between variables. Results are expressed as median and $25^{\text {th }}$ to $75^{\text {th }}$ percentiles. The statistical analysis was performed using
Statistica (StatSoft, USA); $p$ values $<0.05$ were accepted as statistically significant.

The study was approved by the local Bioethics Committee, and all study subjects provided their informed consent.

\section{Results}

On average, the elderly patients with asthma had significantly lower respiratory function, as well as less current asthma control according to GINA criteria and a lower ACT score, although both groups demonstrated similar disease severity based on the ATS Workshop 2000 criteria (Table 1). The distribution of inflammatory cells in the induced sputum varied depending on the age: older patients had a higher mean percentage of eosinophils $(p<0.05)$ and lymphocytes $(p<0.05)$, and a lower percentage of macrophages $(p<0.05)$ in IS (Table 2). However, the elderly and non-elderly asthmatics had similar mean FeNO levels and concentrations of such eosinophilic inflammation markers as periostin in IS, ECP, and total IgE in serum (Table 1). There

Table 1. Clinical characteristics of elderly and non-elderly asthmatics

\begin{tabular}{|c|c|c|c|}
\hline Characteristic & $\begin{array}{c}\text { Elderly } \\
n=15\end{array}$ & $\begin{array}{c}\text { Non-elderly } \\
n=14\end{array}$ & $p$ \\
\hline Female, $n(\%)$ & $13(86.7)$ & $9(64.3)$ & NS \\
\hline Mean age, year \pm SD & $70.7 \pm 3.8$ & $40.6 \pm 6.8$ & $<0.05$ \\
\hline Atopy, $n(\%)$ & $4(31)$ & $6(42.9)$ & NS \\
\hline Ever smoker, $n(\%)$ & $8(53.3)$ & $6(42.9)$ & NS \\
\hline FEV1\% pred., mean \pm SD & $82.2 \pm 20.4$ & $100.7 \pm 12.1$ & $<0.05$ \\
\hline FEV1\% FVC, mean \pm SD & $72.6 \pm 8.1$ & $79.7 \pm 10.7$ & NS \\
\hline \multicolumn{4}{|l|}{ Asthma control ${ }^{*}$} \\
\hline Controlled, $n(\%)$ & 0 & $7(50)$ & $<0.05$ \\
\hline Partially controlled, $n(\%)$ & $7(46.7)$ & $5(35.7)$ & NS \\
\hline Uncontrolled, $n(\%)$ & $8(53.3)$ & $2(14.3)$ & NS \\
\hline ACT score, mean & 18.1 & 21.9 & $<0.05$ \\
\hline Patients with severe asthma ${ }^{* *}, n(\%)$ & $3(20)$ & $2(14.3)$ & NS \\
\hline \multicolumn{4}{|l|}{ Current ICS treatment } \\
\hline Low dose & $3(20)$ & $1(7.1)$ & NS \\
\hline Medium dose & $8(53.3)$ & $8(57.1)$ & NS \\
\hline High dose & $4(26.7)$ & $5(35.7)$ & NS \\
\hline \multicolumn{4}{|l|}{ Inflammatory markers } \\
\hline Serum ECP $(\mu \mathrm{g} / \mathrm{l})$, mean $\pm \mathrm{SD}$ & $11(5.5)$ & $8.1(4.3)$ & NS \\
\hline Total $\operatorname{IgE}(\mathrm{kU} / \mathrm{l})$, mean $\pm \mathrm{SD}$ & $67.6(62.6)$ & $101.9(95.6)$ & NS \\
\hline Periostin in IS $(\mathrm{pg} / \mathrm{ml})$, mean $\pm \mathrm{SD}$ & $8.9(14.4)$ & $8.2(11.3)$ & NS \\
\hline FeNO ppb, mean \pm SD & $22.7 \pm 10.4$ & $24.1 \pm 20.7$ & NS \\
\hline
\end{tabular}


Table 2. Inflammatory cell counts in induced sputum of elderly and non-elderly asthmatics (results are presented as medians and interquartile range)

\begin{tabular}{lccc}
\hline Characteristic & $\begin{array}{c}\text { Elderly } \\
\boldsymbol{n}=\mathbf{1 5}\end{array}$ & $\begin{array}{c}\text { Non-elderly } \\
\boldsymbol{n}=\mathbf{1 4}\end{array}$ & $\boldsymbol{p}$ \\
\hline Total cell count/g sputum & $1.77(0.64-2.5)$ & $1.54(0.72-1.8)$ & NS \\
\hline$\%$ macrophages & $43.3(37-50.4)$ & $55.3(46-70.3)$ & $<0.05$ \\
\hline Macrophages/g sputum & $0.79(0.27-1.22)$ & $0.77(0.42-1.16)$ & NS \\
\hline$\%$ lymphocytes & $19(15-36)$ & $11.1(3.3-19.3)$ & $<0.05$ \\
\hline Lymphocytes/g sputum & $0,24(0.08-1.21)$ & $0.11(0.03-0.32)$ & NS \\
\hline$\%$ eosinophils & $9.5(6-13)$ & $4.6(3-6.6)$ & $<0.05$ \\
\hline Eosinophils/g sputum & $0.17(0.04-0.26)$ & $0.04(0.02-0.11)$ & $<0.05$ \\
\hline$\%$ neutrophils & $17(12-33)$ & $24.1(11-27.6)$ & NS \\
\hline Neutrophils/g sputum & $0.25(0.1-0.57)$ & $0.36(0.14-0.48)$ & NS \\
\hline
\end{tabular}

was no correlation between the number or percentage of eosinophils in the IS and FeNO or ECP in any group.

\section{The presence of respiratory pathogens in the IS}

The molecular technique revealed the presence of $S$. pneumoniae in the IS from all asthmatic patients, both elderly and non-elderly, and $H$. influenzae in half the patients from each group (Table 3). Chlamydophila pneumoniae was detected in one subject from the elderly group and one from the non-elderly group. All sputa were negative for M. pneumoniae, Legionella, and B. pertussis.

Respiratory viruses were detected in the induced sputum from the majority of patients in both groups: in $11(73.3 \%)$ elderly and $10(71.4 \%)$ non-elderly individuals. The most commonly detected virus was Flu A followed by RSV A and RSV B (Table 3). No differences were observed in the detection rates of viruses between elderly and non-elderly patients.

\section{Association between the presence of virus in the IS with clinical and inflammatory markers}

Neither asthma severity according to GINA or ATS criteria nor current asthma control assessed by the ACT were found to correlate with the presence of respiratory pathogens in the IS of asthmatics patients. In elderly asthmatics, but not in the non-elderly group, a few associations between the presence of specific respiratory viruses in the IS and respiratory function/immunological parameters were found. Flu A-positive patients had lower FVC\% predicted than negative ones $(81.8 \%$ pred. \pm 19.9 vs. $100.4 \%$ pred. $\pm 12,9 ; p<0.05$ ). The presence of RSV B was associated with a lower percentage of lymphocytes in the IS $(28.7 \% \pm 12.6$ vs. $5.5 \% \pm 9.5 ; p<0.05)$, and the RSV A-positive patients had lower tIgE concentration in the serum than RSV A-negative elderly individuals $(19.2 \mathrm{kU} / 1$ \pm 17.7 vs. $85.2 \mathrm{kU} / 1 \pm 64.1 ; p<0.05$ ).
Table 3. Respiratory pathogens detected in induced sputum of the elderly and non-elderly asthmatics by molecular techniques

\begin{tabular}{|c|c|c|c|}
\hline Characteristic & $\begin{array}{c}\text { Elderly } \\
n=15\end{array}$ & $\begin{array}{c}\text { Non-elderly } \\
n=14\end{array}$ & $p$ \\
\hline S. pneumoniae & $15(100)$ & $14(100)$ & NS \\
\hline H. influenzae & $8(53.3)$ & $7(50)$ & NS \\
\hline FluA & $8(53.3)$ & $6(42.9)$ & NS \\
\hline RSVB & $6(40)$ & $5(35.7)$ & NS \\
\hline RSVA & $4(26.7)$ & $4(28.6)$ & NS \\
\hline C. pneumoniae & $1(6.7)$ & $1(7.1)$ & NS \\
\hline HRV & $1(6.7)$ & $1(7.1)$ & NS \\
\hline AdV & - & $1(7.1)$ & NS \\
\hline 229E/NL63 & - & $1(7.1)$ & NS \\
\hline
\end{tabular}

\section{Discussion}

This study is the first to use the IS technique to compare detection rates of respiratory pathogens in the airways of elderly and non-elderly patients with asthma. The total number of positive samples and the profile of respiratory pathogens detected in the induced sputum by molecular techniques were found to be similar in elderly and non-elderly individuals. Bronchial asthma, although heterogeneous, has been considered to be, on average, more severe in the elderly population and associated with increased exacerbation rates mostly related to respiratory infections [19]. Our elderly patients tended to have, on average, more severe disease, as expressed by lower respiratory function, and less current asthma control over the previ- 
ous four weeks, demonstrated by GINA criteria and a lower mean ACT score. In addition, the elderly patients had higher sputum eosinophilia and lymphocytosis levels than the non-elderly patients, suggesting the presence of different types of airway inflammation in senior individuals. Although a previous study documents a tendency toward neutrophilic inflammation in the IS from elderly asthmatics, no correlation between neutrophilia and severity of the disease was found [20]. Another study found older asthmatics with fixed obstruction to have a higher percentage of eosinophils and elevated levels of ECP in the induced sputum compared to their peers with chronic obstructive pulmonary disease (COPD), despite an increased percentage of neutrophils in the sputum [21]. Thus, the increased percentage of eosinophils in the IS of elderly patients in our study may reflect the proposed inflammatory profile in the airway mucosa of this population of asthmatics. On the other hand, mean levels of surrogate markers of the airway eosinophilic inflammation (FeNO, ECP, and sputum periostin) were similar in both groups, not confirming differences in the type of inflammation between groups.

Ageing has been associated with several immune abnormalities in both the innate and adaptive immune systems, and consequently with deceased immune response to infections [1]. In this context, the observation of similar detection rate and profile of respiratory pathogens in the induced sputum is rather unexpected. However, our patients had stable asthma during the sputum sampling, and one cannot exclude that the difference in the microbiome between elderly and non-elderly asthmatics might be seen during the disease exacerbations

Although respiratory pathogens have been detected with increased frequency during asthma exacerbations, they may persist in the airways of asthmatics between exacerbation episodes, and it has been postulated that latent or persistent infection may contribute to the chronicity of the airway inflammation [22]. However, a cross-sectional study by Harju et al. [9] reports similar detection rates of respiratory viruses in the IS of patients with clinically stable asthma and healthy controls. Similarly, in a prospective study by Tucharelli et al. [23] the detection rates of 14 respiratory viruses were comparable in clinically stable asthmatics and in healthy controls at three time points. Accordingly, in non-bronchoscopic bronchoalveolar lavage (BAL), the percentage of viral detection did not vary between asthmatic children and controls [24]. In contrast, the presence of HRV in the lung tissue samples from stable patients was found to be higher in asthmatics than in healthy controls [25]. Thus, the presence or absence of respiratory pathogens in BAL or induced sputum may not reflect the persistence of infection of the airway mucosa.

Although the detection rate and profile of respiratory viruses in IS was similar in elderly and non-elderly patients with asthma, the presence of pathogens was associated with some clinical characteristics only in older subjects. The presence of Influenza A virus in the airways of stable asthma patients (without any clinical signs of infection) was associated with lower respiratory function and RSV B with a lower percentage of lymphocytes in the IS. In a study by Woś et al. [25] the presence of HRV was associated with lower spirometric parameters as compared to HRV-negative subjects. Furthermore, in our study the presence of RSV B was associated with a lower percentage of lymphocytes in the IS and the RSV A with lower total IgE concentration in the serum in elderly individuals; however, the significance of this findings remains unclear.

Our study has several limitations. The groups were relatively small, which may have affected the variability of results. The samples were collected during late autumn and winter, which may be connected with more frequent exposure to respiratory infections. Qualitative RT-PCR did not allow active replication indicating active infection to be distinguished from residuals of viral or bacterial DNA or RNA from past infections. The discrepancies between the positivity rates of the respiratory bacteria and viruses shown in the above-mentioned studies may be related to different methods of obtaining samples and detecting pathogens. Supernatants from induced sputum were used as source material, and multiplex RT PCR assays were used for analysis. Harju et al. [9] report higher detection rates of viruses in induced sputum and throat swab samples compared to gelatine-filtered expired air, EBC, or nasal swabs. However, viral identification was not consistent between these methods or during the follow-up period. In a study by Falsey et al. [26] the identification of Bordetella pertussis in IS differed between supernatants and cells from patients with exacerbation of asthma. Hence, our results should be further confirmed in studies involving larger patient populations and, if possible, more direct airway sampling techniques.

\section{Conclusions}

In summary, our findings indicate that, despite some differences in the clinical and inflammatory characteristics of asthma between elderly and non-elderly patients, the microbial composition of IS samples from stable patients is similar.

\section{Acknowledgements}

The authors would like to thank Mrs Dorota Żaromińska, Mrs Barbara Szkudińska, and Mrs Marzanna Jarzębska for their assistance. This study was supported by Medical University of Lodz grant no 503/1-13701/503-01 and Polish National Science Centre grant no. UMO-2013/09/B/NZ6/00746. The authors are partially supported by the Healthy Ageing Research Centre project (REGPOT-2012-2013-1, 7FP).

The authors declare no conflict of interest. 


\section{References}

1. Gupta S, Agrawal A (2013): Inflammation \& autoimmunity in human ageing: dendritic cells take a center stage. Indian J Med Res 138: 711-716.

2. Rantala A, Jaakkola JJ, Jaakkola MS (2011): Respiratory infections precede adult-onset asthma. PLoS One 6: e27912.

3. Madeo J, Li Z, Frieri M (2013): Asthma in the geriatric population. Allergy Asthma Proc 34: 427-433.

4. Meyer KC (2010): The role of immunity and inflammation in lung senescence and susceptibility to infection in the elderly. Semin Respir Crit Care Med 31: 561-574.

5. Dickson RP, Erb-Downward JR, Huffnagle GB (2013): The role of the bacterial microbiome in lung disease. Expert Rev Respir Med 7: 245-257.

6. Lemanske RF Jr, Jackson DJ, Gangnon RE, et al. (2005): Rhinovirus illnesses during infancy predict subsequent childhood wheezing. J Allergy Clin Immunol 116: 571-577.

7. Webley WC, Tilahun Y, Lay K, et al. (2009): Occurrence of Chlamydia trachomatis and Chlamydia pneumoniae in paediatric respiratory infections. Eur Respir J 33: 360-367.

8. Atkinson TP (2013): Is asthma an infectious disease? New evidence. Curr Allergy Asthma Rep 13: 702-709.

9. Harju TH, Leinonen M, Nokso-Koivisto J, et al. (2006): Pathogenic bacteria and viruses in induced sputum or pharyngeal secretions of adults with stable asthma. Thorax 61: 579-584.

10. Marri PR, Stern DA, Wright AL, et al. (2013): Asthma-associated differences in microbial composition of induced sputum. J Allergy Clin Immunol 131: 346-352.

11. Hilty M, Burke C, Pedro H, et al. (2010): Disordered microbial communities in asthmatic airways. PLoS One 5: e8578.

12. Global Initiative for Asthma (2011): Global Strategy for Asthma Management and Prevention 2011 (update). Available from: http://www.ginasthma.org/.

13. Nathan RA, Sorkness CA, Kosinski M, et al. (2004): Development of the asthma control test: a survey for assessing asthma control. J Allergy Clin Immunol 113: 59-65.

14. American Thoracic Society (2000): Proceedings of the ATS workshop on refractory asthma: current understanding, recommendations, and unanswered questions. Am J Respir Crit Care Med 162: 2341-2351.

15. Miller MR, Hankinson J, Brusasco V, et al. (2005): Standardisation of spirometry. Eur Respir J 26: 319-338.

16. American Thoracic Society Workshop (2006): ATS Workshop Proceedings: Exhaled nitric oxide and nitric oxide oxidative metabolism in exhaled breath condensate: Executive summary. Am J Respir Crit Care Med 173: 811-813.

17. Pin I, Gibson PG, Kolendowicz R, et al. (1992): Use of induced sputum cell counts to investigate airway inflammation in asthma. Thorax 47: 25-29.

18. Chmielowicz B, Obojski A, Barczyk A, et al. (2008): Wskazówki metodologiczne Polskiego Towarzystwa Chorób Płuc odnośnie do wykonywania i oceny plwociny indukowanej. Pneumonol Alergol Pol 76: 378-395.

19. Brar T, Nagaraj S, Mohapatra S (2012): Microbes and asthma: the missing cellular and molecular links. Curr Opin Pulm Med 18: 14-22.

20. Ducharme ME, Prince P, Hassan N, et al. (2011): Expiratory flows and airway inflammation in elderly asthmatic patients. Respir Med 105: 1284-1289.
21. Di Lorenzo G, Mansueto P, Ditta V, et al. (2008): Similarity and differences in elderly patients with fixed airflow obstruction by asthma and by chronic obstructive pulmonary disease. Respir Med 102: 232-238.

22. Hogg JC (2001): Role of latent viral infections in chronic obstructive pulmonary disease and asthma. Am J Respir Crit Care Med 164: 71-75.

23. Turchiarelli V, Schinkel J, Molenkamp R, et al. (2011): Repeated virus identification in the airways of patients with mild and severe asthma during prospective follow-up. Allergy 66: 1099-1106.

24. Thavagnanam S, Christie SN, Doherty GM, et al. (2010): Respiratory viral infection in lower airways of asymptomatic children. Acta Paediatr 99: 394-398.

25. Woś M, Sanak M, Soja J, et al. (2008): The presence of rhinovirus in lower airways of patients with bronchial asthma. Am J Respir Crit Care Med 177: 1082-1089.

26. Falsey AR, Formica MA, Walsh EE (2012): Yield of sputum for viral detection by reverse transcriptase PCR in adults hospitalized with respiratory illness. J Clin Microbiol 50: 21-24. 